\title{
On Digital Technology and Music Education
}

\author{
Boyuan Song ${ }^{1}$, Junyi Chen ${ }^{2}$ \\ ${ }^{1}$ School of Humanities, Jiangxi University of Traditional Chinese Medicine, Nanchang, 330004, \\ China \\ ${ }^{2}$ Normal School of Music, Shandong University of Arts, Jinan, 250014, China
}

Keywords: Digital, Technology, Music education.

\begin{abstract}
The impact of digital technology on music is closely related to the life of the public, after the computer involved in music, music recording and dissemination of the way has undergone great changes. Such as the emergence of CD files, MOD files and MP3 files in the form of music recording format, so that many people in their daily lives can be more simple access to music, expanding the popularity of music at the same time, but also expanded the demand for music education surface. Music itself is an elegant art, is able to meet the needs of people's food needs. In the computer technology mature digital technology era, digital technology for music education provides a lot of new teaching ideas and ways. Teachers in the teaching process, you can use more tools for music theory teaching. Students in the process of learning, with the help of digital technology, there can be more independent to explore the opportunities for learning. Based on the background of music development in digital age, this paper analyzes the influence of digital technology on music education and summarizes the application of digital technology in music education.
\end{abstract}

\section{Foreword}

At very early times, some experts have found that music for children's intellectual development and thinking of the rich have a great impact. In some countries such as Europe and the United States, primary and secondary school students to accept musical instruments training more common, China has also joined the instrumental music teaching to nine years of compulsory education. The traditional music teaching, by the teachers, venues and funding and other factors, making music education difficult to expand extensively. But with the gradual improvement of digital technology, audio sampling and digital processing technology can help simplify the process of music teaching, making music teaching for teaching hardware and the needs of the venue greatly reduced. For example, in the teaching of piano lessons, the piano covers an area of relatively large, and each student can have enough chance to come into contact with the pianist is almost impossible. Therefore, with the help of digital technology, in the course of teaching, teachers can use digital audio samples to introduce students to a variety of content, while allowing students to learn after using the digital piano to practice. Digital pianos are smaller than traditional pianos, light in weight and do not need to be regularly maintained. Electronic audio and digital piano is the digital technology era for music education to provide an example of convenience.

\section{Digital era of music development background analysis}

The progress of science and technology is irresistible, and every revolutionary revolution in science and technology will bring about earth-shaking changes in people's lives. When science and technology and the long history of music meet, it burst out of a different spark. Computer technology 
for music theory analysis and research has brought a lot of new ways to achieve. The computer can be used for the analysis of various musical styles, tonality and harmony. People through the sound wave waveform into a series of binary numbers to reproduce the original sound, and ultimately to achieve the digital music. In the relatively mature stage of digital audio technology, musicians use technology to achieve the digital interface of music equipment, that is, more familiar with the MIDI. The final development of science and technology to help the music to achieve a wider range of coverage and the masses for music education more needs.

\section{The Influence of Digital Technology on Music Education}

The combination of digital technology and music has produced a different from the previous computer music, not only to expand and extend the way of music education, but also for the traditional music concept and the actual combination of the way to provide. For students who have received music education, perhaps they are not fully aware of the film-to-television, almost all music-related things are based on computer-generated systems. The following is this article to digital technology for music education some of the impact:

\section{Digital technology makes music education more diverse}

In the music education classroom, the teacher can use the digital technology, to the students from different angles to show the beauty of music. Past music teaching classroom, the teacher can only advanced theory of teaching, and then lead the students to practice the practice. This gap exists in the middle of the period, is likely to lead to students for the theoretical knowledge of the learning effect greatly reduced. And with the help of digital audio files and multimedia teaching technology, teachers in teaching each section of music, can be accompanied by the relevant music materials for students to learn and experience. Second, the teacher in the teaching process, you can use the computer, to achieve the students to lead the creation of fragments. With the help of digital technology, teachers can always let students hear their own ideas of semi-finished products, different students to create music contrast, and even teachers can also help students to the same fragment of the differences to be modified. This provides more practice channels for practical teaching, but also provides the guarantee for the effect of music teaching.

\section{Promote the combination of theory and practice}

In the teaching process of music, every teacher has his own thoughts and thoughts about the pitch, melody, rhythm or playing technique of music, and finally embodies in different teaching methods. And digital technology, the teacher for the relevant teaching content of the innovation provided by the tools and technical assurance, skim the limitations of past experience. Digital technology in promoting the realization of a variety of music theory, but also to help students from all angles to deepen the understanding of music theory and experience.

In the music teaching classroom, with the help of digital technology, harmony of teaching technology can be more intuitive and vivid. Teachers can use the sequencer software to achieve when the teacher playing a chord, the multimedia platform in the classroom will be able to synchronize the music, so that students from the visual and auditory point of view to achieve a high degree of unity. This advantage will be more obvious when teachers teach complex harmony. Teachers can play each note in a phased or step-by-step manner, and then synchronize the music show and the playback of the music content, so that students can be through a short period of time to repeat the study to get a very deep impression. In the process of studying music, students' learning for the score will no longer be a simple note learning. Teachers can learn music in the process of students, the actual performance of the effect of the cycle of play, students can see through the process of ear and ears, carefully analyze the music melody, harmony and structure and other content. Through this way the combination of theory and practice. 


\section{Digital technology offers new opportunities for music learners}

Digital technology provides a simpler way for music learners to realize the spread of their own music works, because audio-formatted music can be sent quickly through the network to where the student wants to send. Second, digital technology also provides students with live music and performance. Students can express music by means of computers and synthesizers. Although the process of music learning is not the main stage of the production of music, but students can in this period of time to enhance themselves, for future creation and performance support, and digital technology is to achieve this end of the process of effective means.

\section{Digital technology reduces the cost of music education}

In the course of past music teaching, teachers need to show students writing or copy the score, for the teacher is to prepare these materials is a small amount of work, and the preservation of physical music for students is also need to pay attention thing. And with the help of digital technology, only a computer, music can be through the program and a simple MIDI keyboard production is completed, and then electronic version of the form to convey the hands of students. Even if there are some errors in the score, the teacher can correct it in time and send the correct version to the student, and the printing costs for the score can be reduced to a certain extent.

At the same time, the use of synthesizers, computers and other electronic tools for teaching, teachers can reduce the number of demand for musical instruments in the classroom, the school in the music equipment spending will drop. Second, the teacher in the beginning of the preparatory stage of the class, do not need to spend a lot of time to debug the instrument. The computer's music equipment can achieve a variety of sound field and sound density of the rapid adjustment, which to some extent, save the time cost of teacher education.

\section{To meet the needs of the public to learn music}

From the beginning of human civilization, in the eyes of ordinary people, music is the art of aristocratic areas and their amateur pastime. This is not only because of the music in the achievements of a long learning process, more importantly, music learners need to get some financial support to support his learning process. So, in most of the eyes of music is a can only appreciate, not close to the art. But in the digital age, people have more access to music. Such as the popularity of music players among students, music has become an indispensable part of the modern life of young people. It is also because of this reason, many young people have the idea of learning music, greatly sturdy the needs of music learning. The digital age technology, but also to a certain extent, reduce the cost of students to participate in music learning, making the current music education can basically meet the needs of learners.

\section{The Application of Digital Technology in Music Education}

Digital technology to help music education to achieve the music, writing and music together, and in the process of real-time dynamic operation, such as the current has been widely used in the study of solfeggio, harmony and music appreciation of the house arrest And so on, can effectively help teachers to solve the traditional music teaching process some of the problems in order to improve the effect of music teaching. The following is the digital technology in the music education process of application analysis:

\section{Interactive teaching methods appear}

In the more mature music teaching classroom, teachers can teach students to carry out different music effects of learning and playing, that is, interactive teaching. This way of teaching, students can achieve real-time trigger at different times, the effect of a variety of different music mix, or to achieve the students and the machine together to play the learning process. This way is very different from the traditional way of teaching, in the past when there is no technical support, it is difficult to imagine, 
but in the era of digital music, interactive teaching can help students improve the unknown exploratory, the future in music The study and implementation, there is greater innovation and progress.

\section{Standardize the learning process}

Solfeggie is the process that every music learner has to go through, and in order to achieve a better school effect, this learning process may not be as easy as imagined. But with the help of modern digital technology, music teaching teachers can carry out some preparatory work before the lesson, making the solfeggio overall teaching process is more scientific and rational. At the same time, technology will greatly reduce the teacher in the course of teaching the chance of playing errors, both to improve accuracy, but also for the teachers to save effort.

\section{Help learners check their own mistakes}

In the course of self-practice of music learners, you can repeatedly scrutinize your own music practice through various computer music equipment, and listen to the recordings of your own music to find your own shortcomings and defects, and then To correct and improve. This avoids the teacher because of too busy and no time for students to correct the problem. And learners can also carry out repeated self-practice through moving tapes to get improved.

\section{To provide more possibilities for writing and composing teaching}

In the past, the process of writing with the music, the prevalence of slow and difficult to modify and other issues. But the use of MIDI keyboard and computer music software and other digital technology tools, you can achieve fast and standardized writing spectrum work. In the classroom, the teacher's impromptu music teaching and student practice stage, will benefit from the computer music technology and speed.

With the exchange of computer networks and MIDI music files, we can more easily get more information. Chinese musicians can have more ways to reach out to different musical styles, such as Latin America's Poseirava and American country music and other musical forms. The progress of digital technology, music teaching for the teaching of the teaching of the duo to provide a wider range of options.

\section{Conclusions}

Computer music related technology, for the public music and music literacy promotion has a very important role. In the future there will be more people take the initiative to seek the opportunity to learn music. With the help of digital technology, whether it is professional music teaching or ordinary music teaching, its teaching methods will be greatly enriched. In the traditional piano class, the theory of teaching and teacher piano playing is the theory and practice of teaching the representative process, which reflects the theory and practice to a certain extent there is a disconnect, and by means of technology, teachers can for students Of the theoretical learning process with the actual performance of the effect. Auditory image and visual image will reach a unified state. The abstract state of the score in the minds of the students will gradually become concrete in the music. The digital technology, but also to achieve the music teaching process of interactive teaching, standardize the solfeggio and help students more independent learning goals. The progress of digital technology in the future will certainly have a greater impact on the music teaching system.

\section{References}

[1] Lian Ping. The Education of Piano Music in Colleges and Universities. Journal of Shantou University, 2005, (02):69-71+92.

[2] Dong Jie. Digital Technology and Music Education. Musical instrument, 2001, (01):53. 
[3] Zeng Qiang. Analysis of Piano Music Teaching in Colleges and Universities Based on Digital Technology. Journal of Jiamusi Education Institute,2012,(05):144-145.

[4] Wu Fang. On the Application of Digital Piano in Music Teaching in Medium Art Colleges. Music time and space,2014,(13):166-167.

[5] [5]Music Communication and Scientific and Technological Progress. Zheng Rongda. Huang Zhong(Journal of Wuhan Conservatory of Music). 2005(04) 